The new feature is the demonstration that this oxidation is brought about by anærobic oxido-reductions. The reactions described seem to occur in all animal tissues which metabolize carbohydrates. They occur also in bacteria. Reaction (1), for example, is quantitatively realized in gonococci.

The work of Peters ${ }^{3}$ and the findings of Simola ${ }^{4}$ suggest that vitamin $B_{1}$ is a co-enzyme for dismutations of the type of the reactions (1) and (3). Fxperiments on tissues of vitamin $B_{1}$ deficient rats and chickens show that such is the case.

Department of Pharmacology,

$$
\text { H. A. Krebs. }
$$

University, Sheffield. July 9.

${ }^{1}$ See also A. Szent-Györgyi, Z. phyziol. Chem., 236, 1 (1935).

${ }^{2}$ See also M. Jowett and J. H. Quastel, Biochem. J., 25, 2181 (1935).

${ }^{3}$ R. A. Peters, Lancet, May 23, 1936.

- P. E. Simola, Suomen Kem., 9, B, 4 (1936).

\section{Length of Saccharide Chains in Glycogens from Different Sources}

EMPLOYing Haworth's 'end-group assay' method, it has already been shown that rabbit liver glycogen formed under normal conditions has a chemical molecule built up of a chain of 12 glucose units ${ }^{1,2}$. Fish (Gadidae) liver glycogen also conforms to this structure ${ }^{2}$.

Haworth afterwards recorded that glycogen (source not mentioned) may also exist derived from 18 units $^{3}$.

I have now examined, by the above method, the glycogens (a) laid down in the liver after oral administration of galactose to fasted rabbits; and (b) from the whole tissue of Mytilus edulis. In each instance the mean number of glucose units in the chemical molecule of the polysaccharide has been found to be 18 .

This fact was revealed only following examination of the cleavage products of the methylated glycogen in question. No apparently significant differences from 12 unit glycogen could be demonstrated by examina. tion of the purified polysaccharides themselves with respect to $[\alpha]_{D}$, reducing power, rate of hydrolysis, or properties of the acetylated or methylated derivatives.

These investigations will be fully reported through the usual channels.

\section{Biochemical Laboratory, Cambridge.}

${ }^{1}$ Haworth and Percival, J. Chem. Soc., 2277 (1932).

'Bell, NATURE, 136, 184 (1935); Biochem, $J .29,2031$ (1935).

${ }^{3}$ Haworth, Pres. Add. to Chem. Sec. of Brit. Ass., p. 41 (1935).

\section{Inhibitory Effect of Phloridzin and Phloretin on Kidney Phosphatase}

THE inhibitory effect of phloridzin on phosphatase action $^{1}$ is well pronounced only when rather high concentrations (about $m / 50-m / 100$ ) of the poison are used. The phloridzin concentrations which are able to prevent any reabsorption of glucose in the kidney are definitely lower ${ }^{2}$ (about $0 \cdot 5-1 \mathrm{mgm}$. per gm. kidney). Phloridzin is hydrolyzed by $N$ hydrochloric acid at $100^{\circ}$ into glucose and phloretin.

The present communication shows that the inhibitory effect of phloretin on kidney phosphatase is about three to four times as high as that of phloridzin. In alkali at $100^{\circ}$ the phloridzin is hydrolyzed into phloroglucin-glucoside and phloretin acid. Here also an increase in the poisonous action (about twice) is observed. Phloroglucin has no poisonous action on phosphatase ; pure phloroglucin-glucoside has not been tested. However, phloroglucin-glucoside inactivates the reabsorption of glucose in the kidney ${ }^{3}$.

Exp. 24/6. Kidney phosphatase; veronal buffer $p \mathrm{H} 8.5$; temp. $38^{\circ} \mathrm{C}$. ; incubation, $60 \mathrm{~min}$.

\begin{tabular}{|l|c|c|}
\hline $\begin{array}{c}\text { Substrate : } \\
\text { glycerophosphate }\end{array}$ & $\begin{array}{c}\text { Ester hydrolysis } \\
\text { (mgm. P) }\end{array}$ & Per cent inhibition \\
\hline Normal sample & $0 \cdot 350$ & \\
Phloridzin $m / 370$ & $0 \cdot 292$ & 15 \\
Phloretin $m / 370$ & $0 \cdot 152$ & $\mathbf{5 7}$ \\
\hline
\end{tabular}

In this connexion, it is of interest that liver and kidney contain great amounts of $\beta$-glycosidases; phloridzin-glycosidase has been found in horse kidney ${ }^{4}$.

University Institute

H. KALCKAR.

of Medical Physiology, Copenhagen. July 10.

${ }^{1}$ Lundsgaard, Biochem. Z., 284, 209 (1933).

' Lundsgaard, Skand. Arch. Physiol., 72, 265 (1935).

${ }^{3}$ Lambrechts, Compt. rend. Soc. biol., 121, 870 (1936).

'Hoffmann, Biochem. Z., 285, 429 (1936).

\section{Steady Performance of Geiger-Müller Counters}

DuE to rapid discharges that take place in a counter, a considerable amount of gas may easily be liberated, or in some cases even adsorbed, causing fluctuations of pressures in the counters. After working for some time, the voltage initially found to be suitable may no longer be so, and may lie beyond the limits within which the counts are independent of variations of applied voltage. This is more likely to occur with low-pressure counters than with highpressure ones, since the working range of voltage diminishes with diminution of pressure. Herein lies the cause of unsteadiness.

One way of remedying this unsteadiness is to increase the pressure in the counter; but this necessitates the use of very high voltages to the counter. Two other ways are open. By the use of suitably high resistances between the counter and the battery, the tendency for a heavy arcing discharge to be initiated by the condenser discharge can be checked. Another way is to use a big reservoir in connexion with the counter volume. The large volume makes changes of pressure negligible.

We have found that counters in which no counting range could be detected easily gave such ranges on the insertion of a ten-litre volume. This arrangement was tested for pressures from $5 \mathrm{~mm}$. up to $10 \mathrm{~cm}$. with counters of different dimensions, air being used in all cases. Tinned copper wire of about $0 \cdot 3 \mathrm{~mm}$. diameter was used for the central electrode. The tinning was done not for any special reason, it being the usual 5 amp. fuse wire. The material of the outer electrode is brass, in thin sheet and enclosed in a sealed glass tube.

Department of Physics,

B. Dasannacharya.

Benares Hindu University.

\section{G. S. RAO.}

